Canadian Studies in Population, Vol. 35.1, 2008, pp. 119-132

\title{
Selecting Social Indicators to Forecast Child Welfare Caseload
}

\author{
Raghubar D. Sharma \\ Research and Outcome Measurement Branch \\ Strategic Policy and Planning Division \\ Ontario Ministry of Children and Youth Services \\ Toronto, Ontario, M5S 2S3, Canada \\ Raghubar.sharma@ontario.ca
}

\begin{abstract}
The purpose of this study is to identify an optimum number of social indicators that provide maximum predictability of child welfare caseloads. The analysis is based on cross-sectional data pooled from the 1996 and 2001 censuses. The unit of analysis is the census division. From an exhaustive review of literature on social indicators and child welfare, we identified ten risk factors. Then, we identified social indicators that were statistically associated with the risk factors. After measuring the statistical association between social indictors with child welfare caseload, this study develops regression models to select and narrow down a list of social indicators with the highest predictability.
\end{abstract}

Key Words: Child welfare, social indicator, statistical relation 
Raghubar D. Sharma

\section{Résumé}

Cette étude a pour but d'identifier un nombre maximal d'indicateurs sociaux qui pourraient le mieux possible prédire les dossiers en cours des services de protection de l'enfance. Notre analyse est basée sur des données transversales fournies par les recensements de 1996 et 2001. L'unité d'analyse est la division de recensement. Après une étude approfondie de la littérature sur les indicateurs sociaux et la protection de l'enfance, nous avons identifié dix facteurs de risque. Puis, nous avons identifié les indicateurs sociaux associés à ces facteurs de risque. Après avoir mesuré la relation statistique entre les indicateurs sociaux et les dossiers en cours de la protection de l'enfance, cette étude a développé des modèles de régression pour sélectionner et cerner la liste des indicateurs sociaux qui offrent le plus haut niveau de prédiction.

Mots-clés : Protection de l'enfance, indicateurs sociaux, relation statistique

\section{Introduction}

An extensive review of literature on child welfare (Fulton 2001) indicates that child welfare caseloads are driven by a diverse client group. They include (i) abused and neglected children; (ii) children or teenagers evicted from their families because of developmental, emotional or behavioural problems; and (iii) parents at the risk of abusing children due to strain in life caused by lack of adequate housing, poverty, psychiatric difficulties, domestic violence etc. The literature further confirms that the social problems faced by these groups vary in severity (Fulton, 2001).

The severity of a social problem can be predicted by its risk factors. A risk factor may be defined as a factor that statistically predicts adverse outcome across the life span (Rae-Grant, 1979). Social indicators are the predictor variables that are statistically associated with a risk factor.

\section{Social Indicators and Risk Factors}

A child welfare caseload is an outcome of a social problem - child abuse and neglect. The purpose of this study is to ascertain the statistical relationships between child welfare caseload and social indicators to determine which indicators are better predictors for forecasting child welfare caseload. From a review of literature (Fulton, 2001), we first identified the following ten 
important risk factors associated with child abuse and neglect. We then identified social indicators associated with each of the risk factors.

\section{Domestic Violence}

Domestic violence is a powerful predictor of maltreatment in childhood (Offord et al, 1989). Kruttschnitt (1994) found exposure to domestic violence to be a predictor of recurrence of child abuse and neglect. Statistics Canada's (1999) Longitudinal Survey of Children and Youth reported that a child who has witnessed such violence, displayed higher rates of emotional and behavioural problems. A child with a violent and inexperienced father is six times more likely to be abused or neglected and it has also been reported that domestic violence is ten times more likely to be prevalent in common-law unions with children than among married couples with children (Fulton, 2001). Accordingly, the social indicators associated with this risk factor are the crime rate in the community and growth of common law unions.

\section{Substance Abuse}

Substance abuse among parents increases the risk of child abuse and neglect by six times the base rate (Chaffing et al, 1996). Other studies that found parental substance abuse associated with child abuse include Herzberger, 1996; Gelles, 1993; Kasim and Cheah, 1995; O'Leary, 1993; and Squires and Bussuttil, 1995. We have selected the alcohol-related death rate in the community as a social indicator related to this risk.

\section{Parental Depression}

Parental depression also increases the risk of child abuse and neglect by six times the base rate (Chaffing et al, 1996). Chaffing et al, (1996) demonstrated by longitudinal research that the probability of serious child abuse and neglect increases by six times when the mother suffers from depression or the father has an antisocial personality disorder or substance abuse disorder. The social indicator used for this risk factor is suicide rate in the community.

\section{Low Socio-economic Status (SES)}

Low socio-economic status (SES) is positively associated with the proportion of mothers with depression and as well as the proportion of fathers with substance 
abuse (Dohrenrend et al, 1992). The communities with low SES lack resources and usually have poor quality of schools, poor housing, and a higher incidence of substance abuse. These communities are also likely to have higher incidence rate of foetal alcohol syndrome and mild retardation among children due to poor parental care, poor medical follow-up and poor nutrition (Fulton, 2001). These outcomes predispose children to neglect and abuse (Fulton, 2001). The proportion of population with less than grade 9 education, proportion of workers in low-paying jobs, and proportion of lone parents in low paying jobs are examples of indicators of low SES.

\section{Risk-taking Behaviour among Youth}

Teenage pregnancy, accidental teenage deaths and offences by young offenders are strong markers of youth risk-taking behaviour that is associated with a higher child welfare caseload (Fulton, 2001). The social indicators associated with this risk factor are teenage birth rate and percent of young offenders among their age groups.

\section{Infant Mortality}

High mortality generally and high infant mortality particularly, in a community is an indicator of low socio-economic status (SES), which in turn predisposes children to neglect and abuse. Ram (1993) used sex differences in mortality as a social indicator of relative status of female in society. Infant mortality being an excellent social indicator of SES of a community can be an indicator of child neglect and abuse in a community.

\section{Poor Early-School Bonding}

Failure to bond to school and early school failure has been identified in recent longitudinal studies to be excellent predictors of conduct disorder and aggression (Fergusson et al, 1995; Gagnon et al, 1995; Tremblay et al, 1992, Tremblay et al, 1995). Conduct disorder and aggression among children is associated with neglect and abuse, and by extension, therefore, data on poor early-school bonding is an indicator of severity of neglect and abuse (Fulton, 2001). Poor performance on Ontario's standardized Grade 3 mathematics, reading and writing tests can be used as an indicator of poor early school bonding and early school failure. 
Selecting Social Indicators to Forecast Child Welfare Caseload

\section{Poverty}

Sameroff (1995) reviewed 14 longitudinal studies and found poverty to be a risk factor of child abuse and neglect. Low income or poverty generates stress on children, parents and disrupts proper functioning of a family. One of the driving forces behind child welfare caseload is stress produced by low income on children and parents. Statistics Canada's Low Income Cut-offs (LICOs), average income, percentage of income from government transfer payments and percentage of social assistance recipients are indicators of poverty.

\section{Housing Insecurity}

Children who are homeless have a higher incidence of injuries and burns, and low educational attainment (Canadian Public Health Association, 1997). The high average rent, the high average owner payments, the higher percentage of renters, a lower average number of rooms in a dwelling and a lower average number of bedrooms in a dwelling in a community can be used as indicators of housing difficulties.

\section{Demographic Structure}

The basic demographic structure of a community is an important determinant of child welfare caseload. The size of the child population, the number of commonlaw unions and the number of lone parents are important demographic indicators associated with child welfare caseload.

\section{Data and Method}

Data on some social indicators (predictor variables) on 49 census divisions (counties/municipalities) of Ontario, Canada were collected from federal and provincial sources. We used cross-sectional data for 1996 and 2001, as timeseries data were not available for many social indicators. To circumvent the lack of time-series data, we used census division as a unit of analysis. Census divisions coincide with counties and municipalities in Ontario. Data on investigations completed and children in care were available from Ontario Association of Children's Aid Societies at the Children's Aid Society level. The catchment areas of most of the Children's Aid Societies coincide with the counties and municipalities in which they reside. However, there are some Children's Aid Societies that cross the boundaries of several counties. This is particularly true for the Children's Aid Societies in northern Ontario. In those 
cases, the data on the number of investigations completed and the number of children in care by Children's Aid Societies were assigned to census divisions by mapping data from census sub-divisions in Children's Aid Societies catchment areas to the census divisions. Accordingly, the data on children in care by Children's Aid Society were assigned to their respective counties or regional municipalities.

Pearson's Correlation Coefficients were calculated to examine the relationship between social indicators and child welfare caseload variables. The correlation analysis only quantifies the strength of the linear relationship between two variables. Multiple regression was used to calculate the relationship between dependent variables and independent variables, and to assess the significance of the independent variables (social indicators) in explaining the variability in the dependent variable (caseload). The terms social indicators, independent variables and predictor variables are used interchangeably in this paper.

The analysis was carried out in several steps. First, statistical correlation coefficients were calculated between dependent and independent variables. Next, full multiple regression models were run by using all the independent variables. The best model free of multicollinearity, which explained the maximum percentage of variation in dependent variable, was chosen for further analysis. Finally, the stepwise regression analyses were carried out with the remaining predictor variables to determine a model, which provided the contribution of each predictor variable to the total variation explained in the dependent variable.

\section{Findings}

There are several types of social indicators that influence child welfare caseload in Ontario. They are demographic (child population, percentage of recent migrant or visible minority population), economic (unemployment and income), social (suicide rate or crime rate) and housing insecurity (rooms or bedrooms per dwelling). Though we have used 2001 census data for most of the independent variables, 1996 data was pooled for the few independent variables where 2001 data was not available. Pearson's Correlation Coefficients were calculated between the dependent variables and some 84 independent variables. The independent variables with statistically significant relationship were used for the further regression analyses. 
Selecting Social Indicators to Forecast Child Welfare Caseload

\section{Statistical Correlation between Child Welfare Caseload and Selected Social Indicators}

There are two types of services that are provided by children's aid societies to families and children at risk of neglect and abuse in Ontario. The services provided to families and their children who still live at home in their community are called non-residential services. Services provided to children who live in foster homes or group homes rather than at home are called residential services. Investigations conducted on the reports received by the Children's Aid Societies are non-residential services and services provided to children in the care of foster parents or in group homes are residential services.

Table 1 gives the values of statistically significant Pearson's Correlation Coefficients for the independent variables (social indicators) with two dependent variables namely, investigations completed and children in care. The number of investigations completed has been chosen as a proxy for non-residential services and the number of children in care has been selected for residential services. Both services combined are referred to as child welfare caseload. There are substantial differences in non-residential and residential child welfare services in terms of funding. Residential services are far more expensive than the nonresidential services.

The correlation analysis shows that child welfare caseload is significantly related to demographic structure, housing insecurity, economic circumstances, social conditions and early school failure. Among the demographic indicators, child population, lack of official language ability, percentage of movers, recent migrants and visible minority have significant correlation with the number of investigations as well as the number of children in care. The municipalities where a higher percentage of the population does not speak or know one of the official languages or have non-official language mother tongue are more likely to have higher child welfare caseloads. Similarly, counties with larger proportion of movers, recent migrants or visible minority population are more likely to have higher proportion of child welfare caseloads. This finding is a reflection of change induced in the population composition of Ontario by a change in immigration source countries. It also suggests that the delivery of Ontario's child welfare programs must be ethnically sensitive. Another demographic variable that shows significant correlation with investigations completed is the percentage of lone parents in a county. The percentage of lone parents may be a reflection of economic hardship as the average family income of lone parents is also correlated with investigations completed. 
Raghubar D. Sharma

Table 1

Statistically Significant Pearson's Correlation Coefficients for Investigations Completed and Children in Care

\begin{tabular}{|c|c|c|}
\hline Indicator & $\begin{array}{c}\text { Investigations } \\
\text { Completed }\end{array}$ & $\begin{array}{l}\text { Children in } \\
\text { Care }\end{array}$ \\
\hline \multicolumn{3}{|l|}{ Demographic } \\
\hline Child population & 0.96 & 0.89 \\
\hline Percent of lone parents in a county & 0.47 & - \\
\hline $\begin{array}{l}\text { Percent of population with non-official } \\
\text { mother tongue }\end{array}$ & 0.32 & 0.34 \\
\hline $\begin{array}{l}\text { Percent of population with no knowledge of } \\
\text { English or French }\end{array}$ & 0.32 & 0.35 \\
\hline $\begin{array}{l}\text { Percent of population with no spoken } \\
\text { English or French }\end{array}$ & 0.33 & 0.35 \\
\hline $\begin{array}{l}\text { Percent of population with non-official } \\
\text { mother tongue }\end{array}$ & 0.3 & 0.32 \\
\hline Percent mover within last 5 years & 0.52 & 0.35 \\
\hline Percent recent migrants & 0.71 & 0.62 \\
\hline Percent visible minority & 0.85 & 0.73 \\
\hline \multicolumn{3}{|l|}{ Housing } \\
\hline Average rooms per dwelling & - & -0.33 \\
\hline Average bedrooms per dwelling & -0.46 & -0.55 \\
\hline \multicolumn{3}{|l|}{ Economic } \\
\hline $\begin{array}{l}\text { Percent with incomes below Low-Income } \\
\text { Cut-offs (LICOs) }\end{array}$ & 0.72 & 0.74 \\
\hline $\begin{array}{l}\text { Sole support parents on Family Benefits } \\
\text { (FBA) }\end{array}$ & 0.97 & 0.96 \\
\hline Total Family Benefits (FBA) recipients & 0.91 & 0.98 \\
\hline General Welfare (GWA) recipients & 0.86 & 0.096 \\
\hline $\begin{array}{l}\text { Average family income for common law } \\
\text { families }\end{array}$ & 0.48 & 0.31 \\
\hline Average family income lone parent families & 0.35 & - \\
\hline
\end{tabular}


Variables related to household crowding also show significant inverse relationship, particularly with children in care. The average number of rooms and average number of bedrooms per dwelling are negatively correlated with child welfare caseload, indicating that the more crowded a dwelling is the higher the risk of child abuse or neglect.

Among economic indicators, income related variables are significantly correlated with the child welfare caseload. The income is an indicator of poverty and income related variables included in this analysis are low-income cut-offs, welfare payments, average family income of common-law and lone parent families.

\section{Results of Regression Analyses}

We developed regression models separately using investigations completed and children in care as the dependent variables. We used social indicators given in Table 1 as the independent variables. Many independent variables were statistically correlated with each other. To reduce the influence of multicollinearity, independent variables with high correlation coefficients with each other were identified from the correlation matrix and were dropped from subsequent analyses. The regressions were repeated until a set of predictor variables without multicollinearity was achieved.

This process was repeated for each dependent variable separately until the model which explained the maximum variation in the dependent variable emerged. The independent variables with statistically significant t-values are given in Table 2 .

Demographic, housing conditions and economic indicators are important predictors of child welfare caseload. Child population, frequency of mobility of parents, household crowding and percentage of parents on welfare can be used to predict the child welfare caseload.

Table 2 only lists those independent variables that showed statistically significant t-values. First model explained $99.6 \%$ of the variation in the investigations completed. Second model explained $97.9 \%$ variation in the children in care. The proximity of R-Square values to those of Adjusted RSquare values suggests that there were not too many variables in the model. Though these models have narrowed down the list of significant predictor variables, we still do not know the individual contribution of significant predictor variables. We carried out a step-wise regression to determine the contribution of each independent variable in explaining variation in the dependent variables. 
Table 2

Results of Full Regression Model: Standardized Estimates for Independent Variables with Significant t-values

\begin{tabular}{lcc}
\hline & \multicolumn{2}{c}{ Dependent Variables } \\
& $\begin{array}{c}\text { Investigations } \\
\text { Completed }\end{array}$ & $\begin{array}{c}\text { Children } \\
\text { in Care }\end{array}$ \\
\hline Demographic & & \\
Child Population & $0.939(4.73)$ & $0.752(3.83)$ \\
\% Mover within Last 5 Years & $0.195(3.21)$ & \\
$\%$ Visible Minority & $-0.443(-2.65)$ & $-0.455(-2.73)$ \\
& & \\
Housing & $-0.204(-3.0)$ & \\
Average Bedrooms per Dwelling & & \\
Economic & $0.352(2,29)$ & \\
Sole Support Parents on Family Benefits & $-0.207(-2.24)$ & $0.452(4.23)$ \\
General Welfare Recipients & & \\
& $\mathbf{0 . 9 9 6}$ & $\mathbf{0 . 9 7 9}$ \\
R-Square & $\mathbf{0 . 9 7 0}$ \\
Adjusted R-Square & $\mathbf{0 8 9}$ & \\
\hline
\end{tabular}

Note: $\mathrm{t}$-values are in parentheses

\section{Most Parsimonious Model \\ with Individual Contribution of Predictor Variables}

We conducted a stepwise regression analysis where in the first step, a predictor variable with the highest R-square value is selected and in the second step, a predictor variable with the second highest R-square is selected. The model continues to select predictor variables this way until no variable with the Rsquare significant at .05 level is found.

Table 3 shows that in the case of investigations completed, child population explains most of the variation followed by visible minority, the low-income cutoffs and the percentage of movers within the last five years. The variable, population with no spoken official language, also emerges significant with less than one percent of variation explained in investigations completed. 
Child population also explained most of the variation in the number of children in care indicating a strong demographic impact on child welfare caseload. In the next steps, the visible minority emerged significant followed by average number of rooms per dwelling. The smaller number of rooms in a dwelling is an indicator of household crowding. Several Canadian studies (Smith and Jackson, 2002 and Reitz, 2005) have indicated that recent immigrants experience higher rates of poverty compared to earlier cohorts of immigrants. As sources of immigration to Canada have shifted to non-European countries, a relatively larger portion of recent immigrants is also from visible minorities. It seems that apart from demographic impact on child welfare caseload, the poverty manifested through visible minority status, household crowding and the population unable to speak one of the official languages is the another main predictor of child welfare caseload.

Table 3

Variation Explained by each Independent Variable in the Dependent Variable

\begin{tabular}{lllll}
\hline \multicolumn{1}{c}{ Predictor Variables } & \multicolumn{2}{c}{$\begin{array}{c}\text { Investigations } \\
\text { Completed }\end{array}$} & \multicolumn{2}{c}{ Children in Care } \\
\hline & t-Values & $\begin{array}{l}\text { Variation } \\
\text { Explained }\end{array}$ & t-Values & $\begin{array}{l}\text { Variation } \\
\text { Explained }\end{array}$ \\
Child Population & 10.7 & $91.6 \%$ & 11.6 & $81.8 \%$ \\
Visible Minority & -5.28 & $2.3 \%$ & -6.7 & $10.3 \%$ \\
$\begin{array}{l}\text { Low Income Cut-offs } \\
\text { (LICOs) }\end{array}$ & 3.03 & $1.0 \%$ & -- & -- \\
$\begin{array}{l}\text { Rooms per Dwelling } \\
\text { Movers within }\end{array}$ & -- & -- & -3.39 & $1.8 \%$ \\
last 5 years & 3.76 & $1.0 \%$ & -- & -- \\
$\begin{array}{l}\text { No spoken English } \\
\text { or French }\end{array}$ & 2.87 & $0.8 \%$ & 2.38 & $0.8 \%$ \\
$\begin{array}{l}\text { Total Variation } \\
\text { Explained }\end{array}$ & - & $96.7 \%$ & - & $94.8 \%$ \\
\hline
\end{tabular}

-- Not statistically significant. 
Raghubar D. Sharma

\section{Conclusion}

The most parsimonious model suggests that changes in child welfare caseload are strongly influenced by demographic, social and economic changes in Ontario. This analysis is based on cross-sectional census data, as time-series data for most social indicators is not available. The most parsimonious model includes at least two indicators (child population and low-income cut-offs) for which at least annual time series data are available. These two indicators can be used to forecast child welfare caseload in Ontario, Canada.

\section{Acknowledgements:}

The views expressed in this paper are those of the author and not necessarily those of the Ontario Ministry of Children and Youth Services.

My thanks to anonymous reviewers and to Patricia Longlade, my colleague for their edits and comments.

\section{References:}

Chaffing, M., K. Kellcher and J.Hollenberg. 1996. "Onset of physical abuse and neglect: psychiatric, substance abuse and social risk factors from prospective community data," Child Abuse and Neglect 20(3): 191-203.

Canadian Public Health Association (CPHA). 1997. "Position Paper on Homelessness and Health," http://www.cpha.ca/cpha.docs/homeless.eng.html

Dohrenwend, B., I. Levac, P. Shrout, S. Schwartz, G. Naveh, B. Link, A. Skodol, and A. Stueve. 1992. "Socio-economic status and psychiatric disorders: The causation-selection issue," Science 255: 946-951

Fergusson, D. M. and L.J. Horwood. 1995. “An early disruptive behaviour, IQ and later school achievement and delinquent behaviour," Journal of Abnormal Psychology 23(2): 183-199.

Fulton, Robert J. 2001. Social Indicators for Child Protection Program in Ontario. Toronto: Research, Planning and Evaluation. 
Gagnon, C., W. Craig, R. Tremblay, R. Zhou, and F. Vitaro. 1995.

"Kindergarten predictors of boys stable behavior problems at the end of elementary school," Journal of Abnormal Child Psychology, 23(6): 751-766.

Gelles, Richard J. 1993. "Alcohol and other drugs are associated with violence they are not the cause," in Current Controversies on Family Violence. Richard J. Gelles \& Donileen R. Loseke (eds). Newbury Park, CA: Sage. Pp 182-196.

Herzberger, Sharon, D. 1996. Violence within the Family. Toronto: Brown \& Benchmark.

Kasim, M. \& I. Cheah.1995. "Childhood deaths from physical abuse," Child Abuse and Neglect 19(7): 847-854

Kruttschnitt, C., J. Mcleod and M. Dornfeld. 1994. "The economic environment of child abuse," Social Problems 40(2): 299-315.

Offord, D., M. Boyle and Y. Ravine. 1989. Ontario Health Study, Children at Risk. Toronto: Queen's Printer.

O’Leary, K. 1993. "Through a psychological lens," in Current Controversies on Family Violence. Richard J. Gelles \& Donileen R. Loseke (eds). Newbury Park, CA.: Sage. Pp 7-30.

Rae-Grant, Naomi. 1979. The State of the Art, a Background Paper on Prevention. Toronto: Queen's Printer, Ministry of Community and Social Services.

Ram, Bali. 1993. "Sex Differences in Mortality as a Social Indicator,” Social Indicators Research 29: 83-108.

Reitz, Jeffrey, Tapping Immigrants' Skills: New Directions for Canadian Immigration Policy in the Knowledge Economy. Montreal: Institute for Research on Public Policy, February 2005.

Sameroff, Arnold. 1995. "General systems theories and developmental psychopathology," in Developmental Psychopathology. Dante Cicchetti and Donald Cohen (eds) New York: J. Wiley. Pp. 659-695. 
Raghubar D. Sharma

Smith, Ekuwa and Andrew Jackson. 2002. "Does a Rising Tide Lift All Boats?,” The Labour Market Experiences and Incomes of Recent Immigrants, 1995 to 1998. Ottawa: Canadian Council on Social Development, 2002.

Squires, T. and A. Busuttil. 1995. "Child fatalities in scottish house fires 198090: a case of child neglect?," Child Abuse and Neglect 19(7): 865-873.

Statistics Canada. 1999. Family Violence in Canada. Catalogue Number 89-114.

Tremblay, R.E., B. Masse, D. Perron, and M. LeBlanc. 1992. "Early disruptive behavior, poor school achievement, delinquent behavior and delinquent personality: Longitudinal analysis," Journal of Consulting and Clinical Psychology 60(1): 64-72.

Tremblay, R.E., L. Pagani-Kurtz, L.C. Masse, F. Vitaro, and R.O. Pihl. 1995. "A bimodal prevention intervention for disruptive kindergarten boys: Its impact through mid-adolescence," Journal of Consulting and Clinical Psychology 63(4): 560-568. 